\title{
Congenital absence of bilateral ICA: an unusual incidental finding in an adult male
}

\author{
Farha Furruqh, ${ }^{1}$ Asthik Biswas, ${ }^{1}$ Suresh Thirunavukarasu, ${ }^{2}$ \\ Ravichandran Vivekandan ${ }^{3}$
}

'Department of Radiology, St Johns Medical College Hospital, Bangalore, Karnataka, India

${ }^{2}$ Department of Neurology, Indira Gandhi Government General Hospital and Post Graduate Institute, Puducherry,

Puducherry, India ${ }^{3}$ Department of Radiology, Indira Gandhi Government General Hospital and Post Graduate Institute, Puducherry, Puducherry, India

\section{Correspondence to} Dr Suresh Thirunavukarasu, sureshy2001@rediffmail.com

Accepted 17 May 2016

\section{DESCRIPTION}

A 55-year-old man presented with headache of 4 weeks duration. There was no history of seizures or vomiting. An MRI of the brain was performed, which revealed no evidence of intracranial space occupying lesion. However, absence of expected flow voids along the course of the petrous and cavernous segments of the intracranial internal carotid arteries (ICA) was noted (figure 1). The sulcal spaces appeared normal with no T2/fluidattenuated inversion recovery hyperintensities (figure 2). There were no signs of chronic ischaemic changes in the neuroparenchyma (figure 2). Intracranial MR angiogram was subsequently performed, which revealed non-visualisation of bilateral ICAs, prominent bilateral vertebral arteries, and prominent basilar and posterior communicating arteries (figure 3). The PCOMs were supplying both middle cerebral arteries and the anterior cerebral arteries (ACA) via the circle of Willis. The A1 segment of the right ACA was absent with the A2 segment being reformed via the anterior communicating artery (figure 3). There was no evidence of 'rete' type collaterals in the intracranial circulation. A CT angiogram (extracranial and intracranial) revealed narrow calibre of both common carotid arteries, with normal external carotid arteries and nonvisualisation of the intracranial ICA on both sides (figure 3). The cervical segment of the right ICA was completely absent, while a short $(1 \mathrm{~cm})$ segment of hypoplastic cervical ICA was noted at the carotid bifurcation on the left side (figure 4). Both carotid canals were hypoplastic (figure 5). There was no evidence of intracranial aneurysm (figure 4).

As no central cause of the headache was found, an ophthalmic examination was performed, which revealed presbyopia. On prescription of bifocal glasses, the patient's symptoms resolved.

Congenital absence of bilateral ICA is very rare, with fewer than 30 cases reported in the literature. However, this number may not represent the true incidence of this condition as individuals may remain asymptomatic, and there is lack of data from large population anatomical studies. ${ }^{1}$ Congenital hypoplasia/aplasia of the ICA should be suspected on imaging when the ICA is not visualised $1-2 \mathrm{~cm}$ beyond the carotid bulb along with a narrow or aplastic carotid canal. Lack of the ICA flow void in MRI can be seen in cases of congenital absence of ICA and in cases with a thrombosed ICA, hence the morphology of the carotid canal helps in making the diagnosis. Another differential diagnosis to consider in this case is Moyamoya disease, which is an idiopathic progressive non-atherosclerotic vasculopathy typically associated with segmental stenosis or occlusion of the ICA. The characteristic imaging finding is that of multiple intracranial collateral vessels at the base of the brain around and distal to the circle of Willis, which, on angiogram, has a 'puff of smoke' appearance. ${ }^{2}$ The lack of these collateral vessels in our patient points to a developmental basis for absent bilateral ICAs.

In the reported cases of ICA hypoplasia/aplasia, there is an increased association with intracranial aneurysms. ${ }^{134}$ This has been postulated to be due either to increased haemodynamic stress through the carotid-vertebral anastomosis or to a developmental disorder in the vasculature. ${ }^{5} 6$ An angiogram is necessary in these cases to detect such aneurysms and also to detect a narrow calibre ICA, which may supply some part of the cerebral circulation. $^{7}$

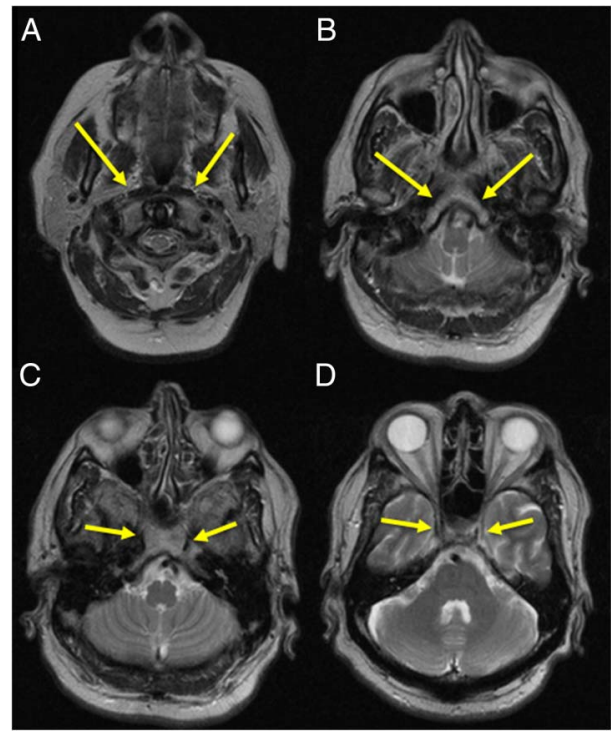

Figure 1 Axial T2 images depicting non-visualisation of flow void in the expected course of the cervical, petrous and cavernous segments of bilateral ICA. Yellow arrows indicate the absent ICA at various levels, (A) cervical part, (B) petrous part, and (C) and (D) cavernous part. ICA, internal carotid arteries. 
Figure 2 Axial images of the brain, (A) T1 image and (B) T2 FLAIR image, which show normal sulcal spaces. (C, $D$ and E) T2 images of the cerebrum and basal ganglia, which are normal. Note the lack of chronic ischaemic changes. FLAIR, fluid-attenuated inversion recovery.
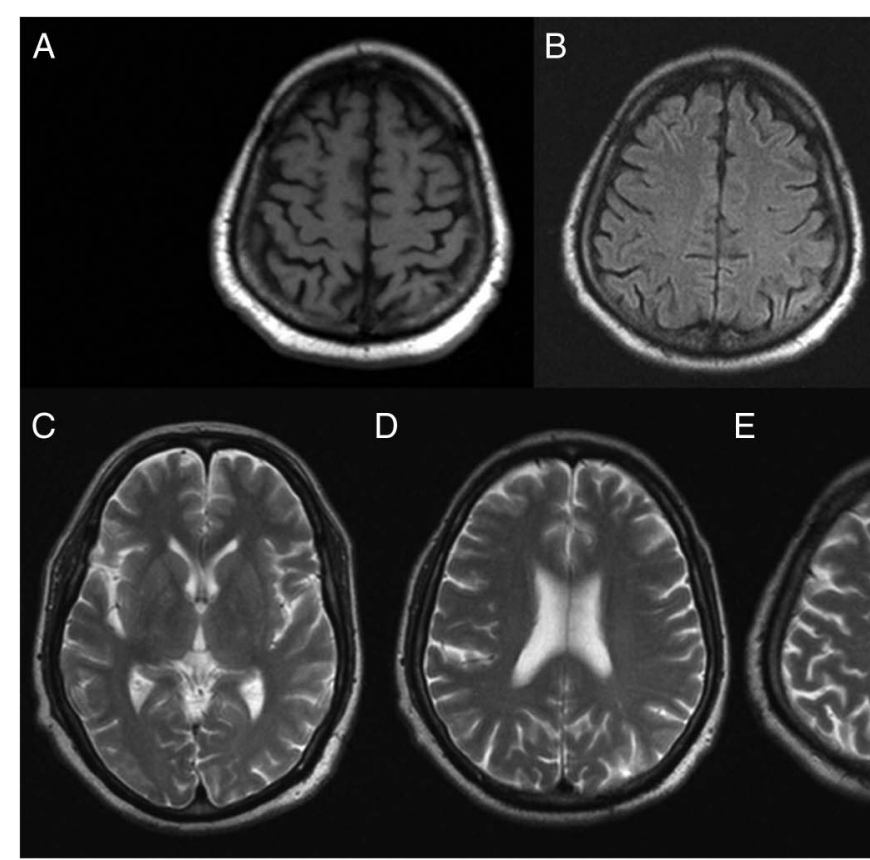

D

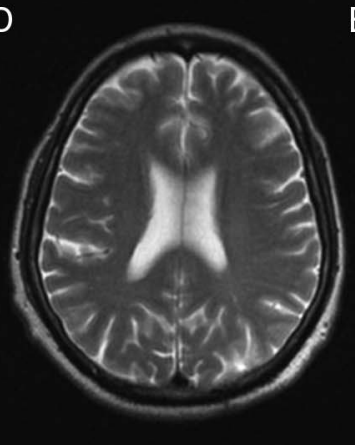

E

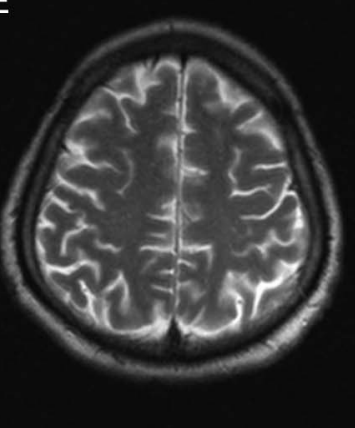

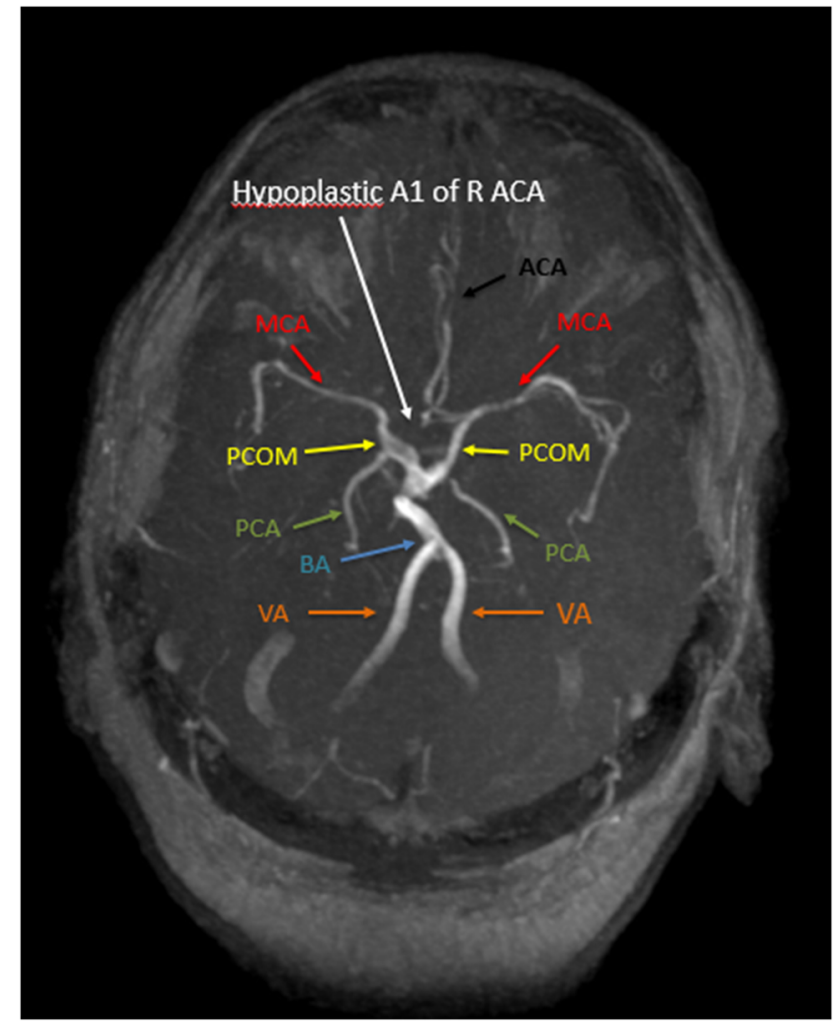

Figure 3 Oblique axial MIP image of intracranial MR angiogram reveals non-visualisation of bilateral ICAs, prominent bilateral vertebral arteries (orange arrows), basilar artery (blue arrow) and posterior communicating (PCOM) arteries (yellow arrows). The PCOMs are supplying both middle cerebral arteries (MCA) and the anterior cerebral arteries (ACA) via the circle of Willis. The A1 segment of the right ACA is absent (white arrow) with the $A 2$ segment being reformed via the anterior communicating artery (ACOM). MCA -red arrows, ACA-black arrow. Note the lack of 'rete' type collaterals in the intracranial circulation. ICAs, internal carotid arteries.

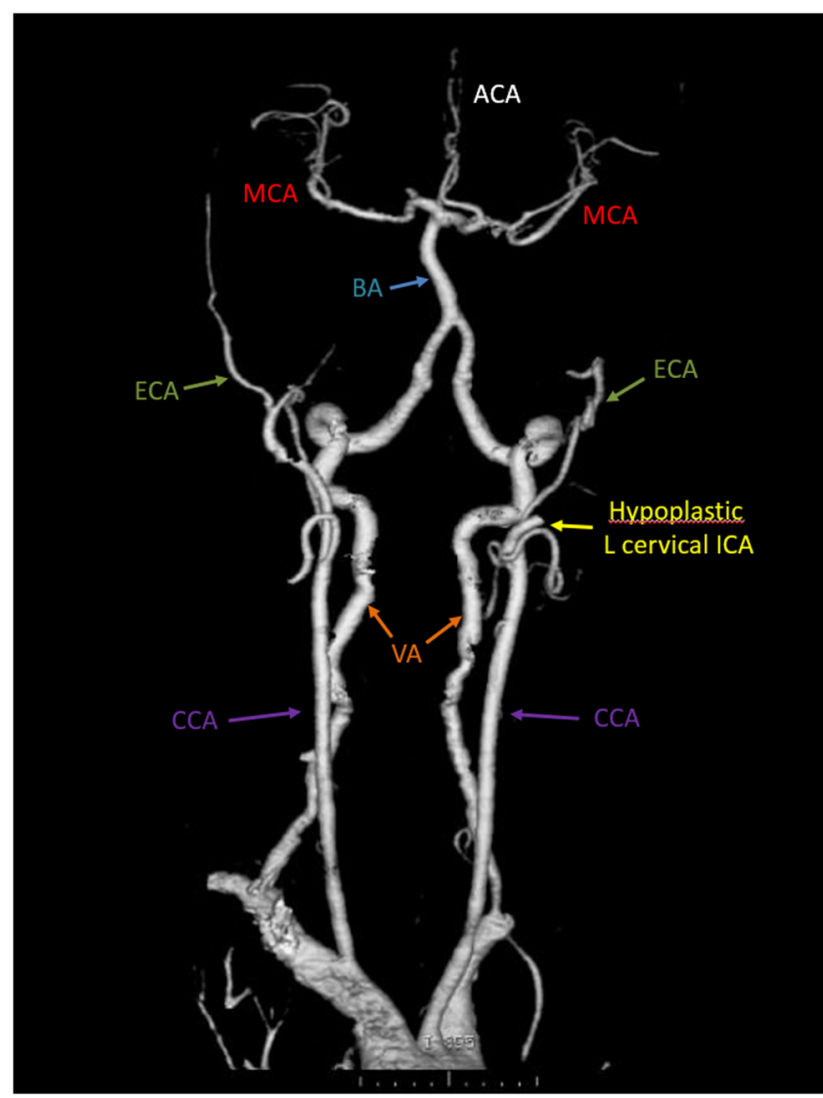

Figure 4 A CT angiogram (extra and intracranial) reveals narrow calibre of bilateral common carotid arteries (CCA), with normal external carotid arteries (ECA) and non-visualisation of the intracranial ICA on both sides. The cervical segment of the right ICA is completely absent and on the left side, a short $(1 \mathrm{~cm})$ segment of hypoplastic cervical ICA is noted at the carotid bifurcation. No aneurysms are noted in the cerebral vasculature. ACA, anterior cerebral arteries; ICA, internal carotid arteries; MCA, middle cerebral arteries. 
Figure 5 Hypoplastic carotid canals (black arrows) in (A) volume rendered image of the skull base, (B and $C$ ) axial $\mathrm{CT}$ section in bone window at level of foramen lacerum and basisphenoid.

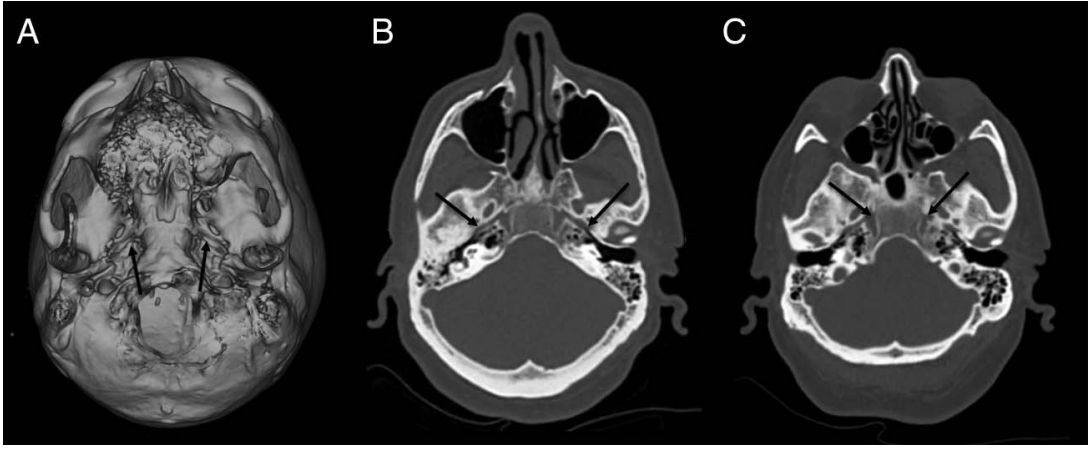

\section{Learning points}

- Congenital absence of the internal carotid arteries (ICA) and acquired occlusion of the ICA are associated with non-visualisation of the vessel lumen on imaging. Congenital absence of the ICA will be associated with a hypoplastic carotid canal, whereas acquired occlusion of the ICA will have a normal carotid canal.

- Congenital absence of bilateral ICA can be differentiated from Moyamoya disease in that the latter has 'rete' type collaterals in the intracranial circulation, while the former does not.

- Congenital hypoplasia/aplasia of the ICA can be unilateral or bilateral, and the cerebral circulation is maintained via various anastomotic pathways between the vertebrobasilar system and the carotid systems via the circle of Willis. Rarely, transcalvarial anastomotic vessels from the external carotid arteries may be noted.

- Increased incidence of intracranial aneurysms is noted in congenital absence of ICA. Screening intracranial angiogram is therefore necessary in these cases.
Contributors FF conceptualised and drafted the manuscript. AB reviewed the literature of the subject and edited the manuscript. ST was the clinician in charge of the patient. RV proofread and edited the manuscript. All the authors reviewed and approved the final manuscript.

Competing interests None declared.

Patient consent Obtained.

Provenance and peer review Not commissioned; externally peer reviewed.

\section{REFERENCES}

1 Briganti F, Maiuri F, Tortora F, et al. Bilateral hypoplasia of the internal carotid arteries with basilar aneurysm. Neuroradiology 2004;46:838-41.

2 Yoon HK, Shin HJ, Chang YW. "IIy sign" in childhood moyamoya disease: depiction on FLAIR and contrast-enhanced T1-weighted MR images. Radiology 2002:223:384-9.

3 Erdem Y, Yilmaz A, Ergün E, et al. Bilateral internal carotid artery hypoplasia and multiple posterior circulation aneurysms. Importance of 3DCTA for the diagnosis. Turk Neurosurg 2009;19:168-71.

4 Siddiqui AA, Sobani ZA. Bilateral hypoplasia of the internal carotid artery, presenting as a subarachnoid hemorrhage secondary to intracranial aneurysmal formation: a case report. J Med Case Rep 2012;6:45.

5 Amano T, Inamura T, Matsukado K, et al. Ruptured saccular aneurysm of a dolichoectatic internal carotid artery in a patient with agenesis of the contralateral internal carotid artery—case report. Neurol Med Chir (Tokyo) 2004;44:20-3.

6 Given CA, Huang-Hellinger F, Baker MD, et al. Congenital absence of the internal carotid artery: case reports and review of the collateral circulation. AJNR Am J Neuroradiol 2001;22:1953-9.

7 Lie TA. Congenital anomalies of the carotid arteries. Amsterdam: Excerpta Medica, 1968:35-51.

Copyright 2016 BMJ Publishing Group. All rights reserved. For permission to reuse any of this content visit http://group.bmj.com/group/rights-licensing/permissions.

BMJ Case Report Fellows may re-use this article for personal use and teaching without any further permission.

Become a Fellow of BMJ Case Reports today and you can:

- Submit as many cases as you like

- Enjoy fast sympathetic peer review and rapid publication of accepted articles

- Access all the published articles

- Re-use any of the published material for personal use and teaching without further permission

For information on Institutional Fellowships contact consortiasales@bmjgroup.com

Visit casereports.bmj.com for more articles like this and to become a Fellow 